\title{
Differences Between Victims of Bullying and Non- victims on Levels of Paranoid Ideation and Persecutory Symptoms, the Presence of Aggressive Traits, the Display of Social Anxiety and the Recall of Childhood Abuse Experiences in a Portuguese Mixed Clinical Sample
}

\author{
Bárbara Cristina Lopes* \\ Faculdade de Psicologia e de Ciências da Educação, Universidade de Coimbra, Coimbra, Portugal
}

\begin{abstract}
Background: Bullying has been considered as a traumatic experience that can lead to paranoid ideation in students (Campbell and Morrison, 2007). This study aimed to explore differences concerning experiences of childhood trauma, the display of social anxiety behaviours, paranoid ideation, and aggressive traits and behaviour in a mixed clinical population with and without persecutory delusions, between individuals who reported being victims of bullying versus those who did not.

Method: A total of 61 individuals with diagnoses of paranoid schizophrenia and social anxiety disorder were given a battery of questionnaires that measured bullying experiences, childhood abuse and experiences of threat and subordination, paranoid ideation, social anxiety behaviours, shame, and aggressive traits and behaviours.

Results: Data on the differences between the victims of bullying and non-victims, in terms of recalling being bullied, showed higher scores on childhood abuse, experiences of threat and subordination within the family, aggressive traits and higher display of persecutory symptoms and less social anxiety behaviours. Conclusion: Bullying is a traumatic phenomenon that is reported by people who suffer from persecutory delusions to a higher degree than those who do not. This study, thus, gives support to the idea that childhood abuse within the family is associated with bullying experiences and that a traumatic infancy may lead to the use of aggressive traits and behaviours to deal with a threatening environment (Bentall and Fernyhough, 2008). This argument raises clinical issues regarding anger management and addressing bullying experiences in individuals with persecutory ideation. Copyright $\odot 2011$ John Wiley \& Sons, Ltd.
\end{abstract}

Key Practitioner Message:

- The importance of bullying experiences in clinical practice: anger management and the relationship between aggressive temperaments and persecutory ideation.

Keywords: bullying, persecutory symptoms, paranoid ideation, aggression, childhood experiences of abuse

\section{INTRODUCTION}

In the twentieth century, a sharp distinction has been drawn between psychosis and neurosis, and this has been embedded in classification systems. Neurotic and psychotic disorders have come to be studied and treated separately. Clinicians assumed that neurotic disorders have a

*Correspondence to: Lopes, Bárbara Cristina, Faculdade de Psicologia e de Ciências da Educação, Universidade de Coimbra, Coimbra, Portugal. E-mail: barbaracslopes@gmail.com psychological aetiology, and psychotic disorders have an organic aetiology. In the last 10 years, however, there has been an attempt to understand the symptoms of psychosis in psychological terms (e.g., Bentall, 1994; Chadwick \& Birchwood, 1994; Frith, 1992; Garety \& Hemsley, 1994), encouraged by clinical evidence that psychological treatment approaches can reduce delusions and hallucinations (e.g., Drury, Birchwood, Cochrane, \& MacMillan, 1996; Kuipers, Fowler, Garety, Chisholm, Freeman, Dunn, Bebbington, \& Hadley, 1998; Tarrier, Yusupoff, Kinney, McCarthy, Gledhill, Haddock, \& Morris, 1998). 


\section{Persecutory Delusions and Trauma}

Cognitive models propose that for some individuals, difficulties in earlier relationships with significant others and interpersonal traumas lead to the formation of negative beliefs about the self and others, such as 'I'm vulnerable' and 'other people are untrustworthy', which may facilitate the development and maintenance of symptoms (Garety, Kuipers, Fowler, Freeman, \& Bebbington, 2001). Furthermore, persecutory delusions are seen as threat beliefs that may emerge as a response to the experience of interpersonal stress and trauma (Freeman, Garety, Kuipers, Fowler, \& Bebbington, 2002). Pre-existing negative beliefs about the self (e.g., as vulnerable, weak and unlovable) may combine with threatening appraisals of others (e.g., implying that others are dangerous or untrustworthy), igniting negative emotions (particularly anxiety), and thereby contributing to the emergence of feelings of threat and paranoia, thus, making the formation of persecutory delusions more likely.

Research seemed to support those models. A recent largescale survey $(n=8580)$ found markedly higher rates of victimizing experiences in people with psychosis compared with other patient groups and the general population (Bebbington, Bughra, Bughra, Singleton, Farrel, \& Jenkins, 2002). A history of trauma has been associated with a great number of positive symptoms of psychosis (Ross, Anderson \& Clark, 1994; Kilcommons \& Morrison, 2005).

Those models were also supported by a high incidence of negative interpersonal events and traumas in people with psychosis, and by evidence from longitudinal studies that suggest adverse environmental experiences can predate the onset of psychosis (Read, Van Os, Morrison and Ross, 2005).

Indeed, a study by Read, Agar, Argyle and Aderhold (2003) found that abuse in childhood or adulthood predicted hallucinations, delusions and thought disorder; whereas, childhood abuse alone was associated with hallucinations. Moreover, a recent study by Shevlin, Dorahy and Adamson (2007), which utilized data from the National Comorbidity Survey to estimate the relationship between occurrences of childhood trauma and self-reported experiences of hallucinations, found that after controlling for background variables (e.g., depression, alcohol dependence etc.), a history of childhood rape and molestation was significantly associated with auditory and tactile hallucinations, and parental neglect was associated with visual hallucinations. Whereas, physical abuse perpetrated by parents was associated with tactile hallucinations. Authors, thus, concluded that positive psychotic symptoms such as hallucinations may be possible indicators of childhood trauma associated with threatening experiences within the family environment.

\section{Bullying and Paranoid Ideation}

Social Mentality Theory has postulated that humans have different social roles (Gilbert, 1989), which are genetically wired, and they display behaviours according to their status defined by the social hierarchy. Thus, human beings, as social creatures, learn to manage social conflicts either by confronting or fleeing, i.e., avoiding. Indeed, according to the nature of the social threat, humans will adopt different defensive behaviours, e.g., submitting to a dominant but threatening a subordinate, or distress calling and searching for a lost parent. Bullying experiences from parents or colleagues are threats that ignite tendencies for specific defences and styles of thinking (Gilbert, 1989, 1998, 2001a; Marks, 1987; Marks \& Nesse, 1994).

For the purpose of this study, we are particularly interested in one type of threat, i.e., bullying in school. Olweus (1993) has defined bullying or victimization as a repeated exposure over time to negative and humiliating actions (with intent) of one or more students. Bullies inflict harm to have control over the victims and to show that they have the power over others by causing discomfort.

Under the light of social mentality theory, bullying is a manifestation of power over others, which lead victims to use certain defences against hostile individuals. Therefore, the presence of paranoid ideation would not be a way to protect self-esteem but a defence against potential threats (Gilbert, Boxall, Cheung, \& Irons, 2005). Indeed, being aware of thwarting, deception, abuse, we know that mistreatment from others could activate 'paranoid' cognitive schema, which in turn leads to specific defensive behaviours such as fight or flee (i.e., avoidance). If an individual thinks that others are always out to get him or her, he or she will take action to avoid and control harmful situations.

Research on bullying is scarce and has, only recently, gained the interest of the research communities. Also, studies on bullying usually dwell on the characteristics of bullies in schools (Olweus, 1993). However, the phenomenon of peer victimization began to be researched with the intent to show the long term negative consequences of being bullied.

A study by Bebbington et al. (2004) found that repeated peer victimization was retrospectively reported more frequently by participants with a psychotic disorder than by those without a psychotic disorder. Also, authors such as Campbell and Morrison (2007) studied the relationship of bullying with the presence of paranoid ideation in a sample of adolescents. They reported three main findings: first, that being bullied at secondary school is related to psychotic phenomena (e.g., to a higher presence of auditory hallucinations); second, negative post-trauma cognitions (e.g., self-blame) about the self and the world related significantly to the predisposition of the psychotic phenomena; and thirdly, positive beliefs about paranoia are related to paranoid thoughts. Campbell and Morrison (2007), thus, argued that bullying can constitute a traumatic event because it may leave an individual prone 
to psychosis. In spite of evidence in favour of an association between trauma and abuse in childhood and adult psychosis, some investigators question specifically the association between peer victimization, and clinical and non-clinical psychotic symptoms (Campbell \& Morrison, 2007).

Hence, a recent study by Scheier et al. (2009) used a prospective cohort design assessing 12-year-old members of the Avon Longitudinal Study of Parents and Children Birth Cohort in Bristol. Their results suggested that peer victimization in childhood, especially if it is chronic or severe, was associated with psychotic symptoms in early adolescence. Bullying was a moderate predictor of psychotic symptoms. Moreover, the severity and chronicity of bullying was mostly related to the likelihood of psychotic symptoms. Scheier and colleagues also found that bullying was not associated with a particular delusion type and had a main effect on the symptoms of psychosis that was not confounded by the variable of family adversity (i.e., living in a threatening family environment). In other words, Scheier et al. (2009) found evidence that suggested the relationship between bullying and psychosis, and this type of victimization may be a developmental marker of a risk factor for psychosis rather than a cause.

Also, research on peer victimization has consistently been found to predict current and future behavioural problems, including depression and social phobia. Indeed, a study by Spencer, Donovan and Brechman-Toussaint (1999) found that socially phobic children were more likely to have experienced bullying, have more negative cognitions, expect more negative outcomes from interactions, to express anxiety. Thus these children have less positive interactions with peers and are more likely to be rejected. This being the case, bullying seems to be related to both paranoid ideation and social phobia.

Nevertheless, it is not clear in what way bullying influences paranoia and social phobia and what psychological mechanisms may mediate these relationships. For example, are there differences between victims of bullying and non-victims concerning paranoid ideation, fear of rejection, submissive displays of behaviours, shame and preoccupation with what other people think?

Since it has been suggested that it is not the recall of traumatic experiences in non-clinical samples, but the presence of negative beliefs about the self and others, that is strongly associated with a predisposition to paranoia (Gracie, Freeman, Green, Garety, Kuipers, Hardy, Ray, Dunn, Bebbington, \& Fowler, 2007), we attempted to study the experience of bullying as a traumatic phenomenon in a clinical sample and whether bullying is related to a specific diagnosis.

Our general aim was to study bullying as a traumatic experience and its associated variables of ranking, parental abuse and shame.
Thus, we presented the following hypotheses:

1. Victims of bullying should differ from non-victims. Therefore, these victims should show higher levels of paranoid ideation, physical and verbal aggressive behaviour and subordination behaviours. According to the social ranking theory, children show submissive behaviours towards parents to avoid rejection, which is a sign of a lower rank, and this behaviour may make them prone to bullying. Victims should also have higher instances of recalling threatening experiences in the family environment and physical abuse from their fathers, as well as experiences of antipathy/hostility / rejection and neglect from both parents.

2. Victims of bullying should also show less signs of social phobia (such as fear of negative evaluations), as we expect bullying to be associated with paranoid ideation, diagnosis of paranoid schizophrenia and psychotic symptomatology (such as positive symptoms, e.g., thought disturbance).

\section{METHOD}

\section{Participants}

We recruited a heterogeneous sample of 61 individuals suffering from paranoid schizophrenia and from social anxiety disorder. All individuals suffering from social anxiety disorder were recruited from outpatient clinics; whereas, 10 individuals suffering from paranoid schizophrenia were recruited from outpatient clinics, and 11 were inpatients at the State Psychiatric Hospitals of Magalhaes Lemos, Sobral Cid and Hospitais Universitarios de Coimbra. This study obtained ethical approval from each hospital's ethical committee.

\section{Procedure}

Patients were referred by their psychiatrists who treated them for more than 1 year and who were professionals with more than 20 years of clinical experience. The diagnoses were made by the psychiatrists on the basis of the Brief Psychiatric Rating Scale (BPRS) interview and a review of case notes (Lukoff et al., 1986); whereby, the BPRS' item 11 (suspiciousness/paranoid ideas) served as an index for delusions of persecution (BPRS $11>3$ points [mild symptoms]). Thirty-one participants showed the presence of persecutory delusions at the time of testing.

Psychiatrists also used the Anxiety Disorders Interview Schedule-Revised (Di'Nardo \& Barlow, 1988) with minor modifications to adapt to the Diagnostic and Statistical Manual of Mental Disorders, Fourth Edition (DSM-IV) 
criteria in diagnosing social phobia. They also asked patients to fill in the Social Interaction and Performance Anxiety and Avoidance Scale (SIPAAS) questionnaire where scores $>115$ for the subscale of distress/anxiety and scores $>105$ for the subscale of avoidance served as an index for social phobia, (Pinto-Gouveia, Cunha \& Salvador, 2003) and the Fear of Negative Evaluations (FNE) by Watson and Friend, 1969. Both are valid instruments that measure reliably the presence of social phobia symptomatology (Pinto-Gouveia et al., 2003).

The experience of persecutory delusions and auditory hallucinations was assessed by psychiatrists in an interview using key questions ('Did you recently felt that you were being persecuted?', and 'Did you ever feel that there was a conspiracy against you?'; 'Did you hear frequently malevolent voices?'). Patients that answered affirmatively to these questions were included in the sample if they did not present negative symptoms of psychosis at the time of testing and were not remitted.

All patients were Portuguese and resided in the city where they attended the hospital services. They also had been in therapy for more than 1 year and were being medicated at the time of testing with antipsychotic medication and nervous system inhibitors. Exclusion criteria included history of serious head injury and/or central nervous system disease, and current substance abuse (as per DSM-IV criteria).

Each patient was informed about the protocol, given a brief description of the nature of the study and asked to sign the consent form before completing the selfreport questionnaires. Confidentiality and anonymity were assured.

\section{MEASURES}

The Paranoia Checklist (PC) (Freeman et al., 2005a), which was translated and adapted into Portuguese by Lopes \& Pinto-Gouveia, 2010 in press, is an 18-item self-report multidimensional scale developed to measure paranoid ideation. None of the items from the original version were changed. It includes items assessing ideas of persecution (e.g., 'I need to be on my guard against others') and reference (e.g., 'There might be negative comments being circulated about me'). Items are each rated on five-point Likert scales for frequency, degree of conviction and distress, and it has excellent internal consistency (Cronbach alpha $>0.90$ ) and good convergent validity. The Cronbach alphas for this study were: 0.96 (frequency), 0.94 (conviction) and 0.95 (distress).

The Submissive Behaviours Scale (SBS) (Allan \& Gilbert, 1997), which was translated and adapted into Portuguese by Lopes \& Pinto-Gouveia, 2010 in press, is a 16-item scale assessing a number of behaviours considered as submissiveness (e.g., 'I agree that I am wrong, even though I know I'm not'). Each behaviour is rated on a five-point scale (never $=0$, always $=4$ ). Items are rated as 0 (never) to 4 (always). Higher scores indicate greater use of submissive behaviours. The submissive behaviour scale has satisfactory internal consistency and test-retest reliability, and it has been shown to be strongly correlated with psychopathology in both clinical and non-clinical groups (Allan \& Gilbert, 1997). This scale showed good reliability presenting a Cronbach alpha of 0.89 .

The Other as Shamer Scale (OAS) (Allan, Gilbert, \& Goss, 1994; Goss, Gilbert, \& Allan, 1994), which was translated and adapted into Portuguese by Lopes, B.; Pinto-Gouveia, J. and Castilho, P., 2009 cited in Lopes, B. and Pinto-Gouveia, J., 2010 in press, is an 18-items scale that asks respondents to indicate the frequency of their feelings and experiences to items such as 'I feel insecure about others' opinions of $\mathrm{me}^{\prime}$ and 'Other people see me as small and insignificant' on a five-point Likert scale (0-4). This scale offers a measure of beliefs on 'being looked down on' (seen as in a low rank), shame or stigmatizing shame (Gilbert, 1998). Higher scores indicate high levels of shame about how others view them (i.e., external shame). This scale has shown satisfactory internal consistency (e.g., Cronbach alpha 0.92 Gilbert, Boxall, Cheung, \& Irons, 2005). This study presented a Cronbach alpha of 0.94 .

The Bully/Victim Questionnaire (BVQ) (Olweus, unpublished) was adapted into Portuguese by (Lopes \& Pinto-Gouveia [2010], in press). In this study, and since our sample is comprised mainly of young adults, we used the reformulated version of the questionnaire (already applied in non-clinical populations) in such a way that it asked participants to recall and report experiences of bullying since childhood to the present moment, and we added a question that specifically tackled workplace bullying, as well as asked a) whether people were bullied at work; b) what type of bullying behaviours occurred (e.g., passed over for promotions; harassed by colleagues etc.); c) by whom (an individual or a group of colleagues, a superior etc.); and d) localization (where the bullying occurred). We only used the section examining victimization, and this concerned the participants' experiences of being bullied and sexually harassed by colleagues (i.e., unwanted touching, rubbing etc.) (31 questions). This questionnaire has been widely used in the literature (Smorty, Del Buffa, Maggino \& Bacchereti, 2005); although the psychometric properties have not been publicized, the concurrent validity of self-reported bullying (0.60-0.70) has been established through comparisons with peer nominations (Olweus, 1993). Evidence for the construct validity of 'being victimized' has also been reported (Solberg \& Olweus, 2003). Lopes \& PintoGouveia (2009, in press) reported that the Portuguese adaptation of this scale in a non-clinical sample had a Cronbach alpha of 0.60 . It is important to note, however, that studies in Portugal reported data from this scale 
mostly to formulate a revised anti-bullying policy for schools (Matos, Lima \& Carvalhosa, 2001).

The Beck Depression Inventory-2 (BDI-2) (Beck, Rush, Shaw, \& Emery, 1979) is a 21-item scale that measures the severity of self-reported depressive symptoms (Beck, Steer, \& Brown, 1996). Each item is rated on a Likert scale from 0 to 3 with total scores ranging from 0 to 63 . Higher scores reflect an increased severity of depressive symptoms. The BDI-2 has demonstrated good reliability, substantial convergent validity (correlates highly with other validated measures of depression) and good discriminant validity, and it has been widely used in research (Beck, Steer, \& Brown, 1996). The BDI-2 presented a Cronbach alpha $=0.84$.

The Expanded Brief Psychiatric Rating Scale (BPRS), by Ventura, Green, Shaner, and Liberman (1993), is a 24-item semi-structured interview that measures psychiatric symptom severity (Lukoff et al., 1986). The BPRS was used to assess for the presence of persecutory delusions in clinical participants. BPRS items are rated on a scale ranging from 1 ('not present') to 7 ('extremely severe'). The BPRS comprises four factor scores: anergia/avolition (emotional withdrawal, motor coordination, uncooperativeness and blunted affect); thought disorder (grandiosity, suspiciousness, hallucinatory behaviour and unusual thought content); affect (anxiety, depressive mood, somatic concerns and guilt); and disorganization (conceptual disorganization, tension and mannerism/posturing). For the purpose of this study, we added up the scores of items that measured suspiciousness. So, we had an extra factor named hostility (see Tariot, Podgorski, Blazina \& Leibivici, 1993). The researcher who administered the BPRS was trained to obtain acceptable levels of reliability with a criterion-trained rater (ICC $=0.80+($ Ventura, Green, Shaner, \& Liberman, 1993)).

The Fear of Negative Evaluation (FNE) (Watson \& Friend, 1969) was translated and adapted into Portuguese by Pinto-Gouveia et al. (1986). Social anxiety has often been measured with the FNE. The FNE is a 30-item scale that assesses the fear of being negatively judged and evaluated by others (peers, superiors etc.). Responses are given in a Likert-type scale ranging from 1 (not at all) to 5 (extremely). Scores may range from 30 to 150, and the higher the scores, the more fear of negative evaluations. The Portuguese version of the FNE showed good psychometric properties with a Cronbach alpha of 0.87 for normal populations (PintoGouveia et al. 1986). In this study, the scale presented a Cronbach alpha of 0.90 .

The Aggression questionnaire (AQ) (Buss \& Perry, 1992) was translated and adapted into Portuguese by Lopes and Pinto-Gouveia (2010), in press.). This scale tackles several components of anger. Participants have to rate in a fivepoint Likert scale how much each statement reflects their character and behaviour ( $1=$ not at all to $5=$ very much).
The scale is comprised of four subscales: physical aggression, verbal aggression, anger and hostility. Physical aggression involves striking another person, hitting and breaking things. Verbal aggression involves disagreeing with people and being argumentative. Anger focuses on subjective experiences and feelings such as flaring up, irritated and being hot-headed. Hostility is focused on various domains of feeling cheated and unfairly treated, and mild paranoia such as wondering why people are nice to someone. Higher scores indicate more anger, hostility and aggressive behaviours. These factors have good internal consistency and stability over time. In our study, the Cronbach alphas for each dimension were the following: 0.84 (physical aggression); 0.69 (verbal aggression); 0.80 (anger); and 0.81 (hostility).

The Early Life Experiences Scale (ELES) by Gilbert, Cheung, Grandfield, Campey and Irons (2003), was translated and adapted into Portuguese by Lopes and Pinto-Gouveia (2010, in press). This questionnaire was devised to measure childhood memories wherein the individual perceived a threat within the family or felt as a subordinate in relation to family members. The ELES is composed of three subscales: 'threat', 'submissiveness' and '(Un)valued'. Gilbert et al. (2003) argued that the third factor tapped into experiences that revealed a more cooperative and affiliate relational style.

The response measure consisted of a Likert type scale that required participants to answer how true the statement about their childhood was, from ' $0=$ completely untrue to $5=$ very true'. Three items were reversed to minimize response bias and standard type of responses. The minimum score for this scale was 16 and the maximum, 80. Gilbert et al. showed that this scale was reliable (Cronbach alphas: total 0.92; 'threat' $=0.84$; 'submissiveness' $=0.86$ and '(Un)valued' $=0.71)$. This scale showed the following Cronbach alphas of the total (0.89) and subscales of 'threat' (0.86), 'submissiveness' (0.76) and '(Un)valued' (71).

Social Interaction and Performance Anxiety and Avoidance Scale (SIPAAS) (Pinto-Gouveia, Cunha \& Salvador, 2003) is a self-report questionnaire that tackled the anxiety or fear people show when facing several kinds of social situations $(n=44)$. For each situation, respondents were asked to indicate both the degree of fear or anxiety the situation provokes or would provoke and how frequently they avoid or would avoid that situation. A four-point (1-4) rating scale was employed. The scale is formed by two subscales: distress/anxiety subscale and the avoidance subscale. The higher the scores, the more anxiety or avoidance of social situations. Pinto-Gouveia et al. (2003) have shown good internal consistency for this scale both in clinical and non-clinical populations. In our study, Cronbach alphas for each subscale were 0.94 (anxiety) and 0.93 (avoidance). 
The Childhood Experience of Care and Abuse Questionnaire (CECA.Q), by Bifulco, Bernazzani, Moran and Jacobs (2005), was translated and adapted into Portuguese by Carvalho (2006). The CECA.Q is a questionnaire that was based upon the responses obtained in a retrospective interview about childhood experiences such as parental negligence, physical abuse and sexual abuse. This questionnaire is composed of 17 items that tackle parental care issues. From the 17 items, eight items tackle experiences of parental antipathy, i.e., hostility, coldness and rejection, towards their child; whereas, the remaining nine items tackled experiences of neglect, i.e., parental non interest and sloppiness concerning the essentials in the child's care, health and well-being (e.g., feeding, dressing the child etc.). Participants have to respond to the 17 items about antipathy and neglect for both the maternal figure and the father figure. Answers are given in a Likertresponse type scale: 1 (yes totally) to 5 (not at all).

This questionnaire also addresses physical abuse that is defined as repeated physical attacks perpetrated by family members such as the mother, father or other family members against the child, e.g., smacking, kicking and punching. As with antipathy/neglect, respondents have to answer separately for the mother figure versus the father figure concerning physical abuse. At last, CECA. $Q$ also addressed experiences of sexual abuse. Sexual abuse is defined as physical contact of a sexual nature initiated and performed by an adult in relation to a child, and it excluded the experiences of consented sexual relations between peers. The experiences of sexual abuse were divided into two types of questions: the first type tackled the first sexual experience; and then the second type went on to address issues about sexual abuse and is graded in severity, as it includes the case of rape. The original authors of this scale reported Cronbach alphas of 0.80 for antipathy and 0.81 for neglect (Bifulco et al., 2005). In our study, antipathy showed a Cronbach alpha of 0.89 and neglect of 0.87 .

\section{RESULTS}

\section{Participants' Descriptives}

From the total sample, $40(65.6 \%)$ were men and 21 $(34.4 \%)$ were women. Also, $77 \%$ of the patients were single $(n=47), 16.4 \%(n=10)$ were married, $3.3 \%(n=2)$ were widows and $1.6 \%(n=1)$ lived together. Social class was measured in a self-report questionnaire that asked about their income and educational background. Hence, results showed that $24.6 \%$ of patients came from a low social class $(n=15)$, the other $24.6 \%$ came from a middle social class $(n=15), 6.6 \%(n=4)$ came from an upper social class and $21.3 \%(n=13)$ were currently students; whereas, $18 \%(n=11)$ were unemployed and $4.9 \%(n=3)$ were retired. The mean age was $\mathrm{M}=32.90, \mathrm{SD}=9.765$ and years of education $\mathrm{M}=12.88, \mathrm{SD}=3.979$. From the total sample, 31 individuals had a clinical diagnosis of paranoid schizophrenia (as per DSM-IV criteria 245.30). This group was comprised of 22 men and 9 women with a mean age $\mathrm{M}=28.67$ and with a mean for years spent at school of $\mathrm{M}=11.5$ years, which means an education level equivalent to secondary school attendance. However, 30 individuals had a clinical diagnosis of social anxiety disorder (as per DSM-IV-IV criteria 300.23). From this group, 18 were men and 12 were women. The mean age was of $M=26.93$; their level of education was higher than the individuals diagnosed with paranoid schizophrenia $\mathrm{M}=14.30$ (graduate level). It should be noted that only the scores of the men and women on the 'antipathy by father' and 'neglect by father' items of the CECA. Q had statistically significant differences. Men significantly showed more experiences of antipathy and neglect by their fathers on the CECA.Q than women $(t(59)=3.721$, $p=0.001)$ for 'antipathy by father' and $(t(59)=4.535)$, $p=0.000)$ 'for neglect by father', respectively. There were no significant differences between the men and women concerning age, civil and socio-economic statuses.

\section{Differences between Victims of Bullying and Non-Victims of Bullying at School}

From the sample of 61 individuals, $n=42$ (68.85\%) recalled being a victim of bullying. From the total sample of victims of bullying, $n=25(59.52 \%)$ had a diagnosis of paranoid schizophrenia; whereas, $n=17(40.47 \%)$ had a diagnosis of social phobia. As expected, the individuals that suffered from paranoid schizophrenia reported more statistically significant experiences of bullying than those who suffered from social anxiety $\chi^{2}(1,61)=4.087$, $p<0.05$. We tested for differences between participants that acknowledged being victims of bullying, who we classified as victim of bullying (VB) $n=42$, versus participants that did not report being victims of bullying, who we classified as non-victims of bullying (NVB) $n=19$. The VB group showed a lower education level $(\mathrm{M}=12$ years of education) than the NVB group ( $M=14.84$ years of education), and this difference was statistically significant $(t(59)=2.800, p<0.010)$. The VB showed a statistically significant difference concerning the distribution of sexes to the NVB $\chi^{2}(1,61)=6.733, p<0.010$. This suggested that there were more males $n=32$ than females $n=10$ that reported being victims of bullying at school. Tables 1 and 2 show that there were no significant difference between the sexes concerning age, civil and socio-economic statuses.

Since being a victim of bullying or not was a categorical variable, which was based on 'yes' or 'no' answers of participants to the question 'did you experience 
Table 1. Socio-demographic characteristics of the mixed clinical sample

\begin{tabular}{|c|c|c|c|c|c|c|}
\hline \multicolumn{2}{|c|}{ Paranoid schizophrenia } & \multirow{2}{*}{$\frac{\text { Male }}{\%}$} & \multicolumn{2}{|c|}{ Female } & \multicolumn{2}{|c|}{ Total } \\
\hline$(n$ 31) & $n$ & & $n$ & $\%$ & $n$ & $\%$ \\
\hline & 22 & 71 & 9 & 29 & 31 & 100 \\
\hline \multicolumn{7}{|l|}{ Ages } \\
\hline $17-30$ & 2 & 9 & 3 & 33.3 & 5 & 16 \\
\hline $31-37$ & 8 & 36.1 & 2 & 22.2 & 10 & 32.2 \\
\hline $38-45$ & 7 & 31.7 & 2 & 22.2 & 9 & 29.1 \\
\hline $46-50$ & 3 & 13.5 & 2 & 22.2 & 5 & 16.1 \\
\hline $51-61$ & 1 & 4.5 & 0 & 0 & 1 & 3.2 \\
\hline $61-70$ & 1 & 4.5 & 0 & 0 & 1 & 3.2 \\
\hline \multicolumn{7}{|l|}{ Years of education } \\
\hline$\leq 4$ & 2 & 9 & 1 & 11.1 & 3 & 9.7 \\
\hline$\leq 9$ & 7 & 31.8 & 2 & 22.2 & 9 & 29.1 \\
\hline$\leq 12$ & 7 & 31.8 & 0 & 0 & 7 & 22.6 \\
\hline 13 & 1 & 4.5 & 1 & 11.1 & 2 & 6.5 \\
\hline 15 & 1 & 4.5 & 0 & 0 & 1 & 3.2 \\
\hline $16-19$ & 4 & 18.1 & 5 & 55.5 & 9 & 29 \\
\hline \multicolumn{7}{|l|}{ Civil status } \\
\hline Single & 13 & 59.1 & 7 & 77.8 & 20 & 64.5 \\
\hline Married & 2 & 22.7 & 2 & 22.2 & 7 & 22.6 \\
\hline Divorced & 2 & 9.1 & 0 & 0 & 2 & 6.5 \\
\hline Widow & 1 & 4.5 & 0 & 0 & 1 & 3.2 \\
\hline \multirow[t]{2}{*}{ Union } & 1 & 4.5 & 0 & 0 & 1 & 3.2 \\
\hline & $\mathrm{M}$ & SD & $\mathrm{M}$ & SD & $t$ & $p$ \\
\hline Age & 40.13 & 9.468 & 35.11 & 10.752 & 1.222 & 0.243 \\
\hline \multirow[t]{2}{*}{ Years of education } & 10.86 & 3.919 & 13.11 & 5.418 & -1.295 & 0.289 \\
\hline & \multicolumn{2}{|c|}{ Male } & \multicolumn{2}{|c|}{ Female } & \multirow{2}{*}{\multicolumn{2}{|c|}{ Total\% }} \\
\hline Profession & $n$ & $\%$ & $n$ & $\%$ & & \\
\hline Student & 1 & 4.5 & 1 & 11.1 & 2 & 6.5 \\
\hline Retired & 3 & 13.6 & 0 & 0 & 3 & 9.7 \\
\hline Unemployed & 3 & 13.6 & 1 & 11.1 & 4 & 12.9 \\
\hline \multicolumn{7}{|c|}{ Social economical class } \\
\hline Low class & 9 & 40.9 & 3 & 33.3 & 12 & 38.7 \\
\hline Medium class & 5 & 22.7 & 2 & 22.2 & 7 & 22.6 \\
\hline High class & 1 & 4.5 & 2 & 22.2 & 3 & 9.7 \\
\hline Social anxiety & \multicolumn{2}{|c|}{ Male } & \multicolumn{2}{|c|}{ Female } & \multicolumn{2}{|c|}{ Total } \\
\hline \multirow{2}{*}{$(n=30)$} & $n$ & $\%$ & $n$ & $\%$ & $n$ & $\%$ \\
\hline & 18 & 60 & 12 & 40 & 30 & 100 \\
\hline \multicolumn{7}{|l|}{ Ages } \\
\hline $18-23$ & 6 & 33.5 & 1 & 8.3 & 7 & 23.2 \\
\hline $24-28$ & 7 & 39 & 7 & 58.3 & 14 & 46.7 \\
\hline $29-34$ & 4 & 22.3 & 3 & 25 & 7 & 23.3 \\
\hline $35-40$ & 1 & 5.6 & 1 & 8.3 & 2 & 6.6 \\
\hline \multicolumn{7}{|l|}{ Years of education } \\
\hline$\leq 9$ & 2 & 11.1 & 0 & 0 & 2 & 6.7 \\
\hline $10-12$ & 8 & 44.5 & 1 & 8.3 & 9 & 29.9 \\
\hline $13-14$ & 4 & 22.2 & 0 & 0 & 4 & 13.4 \\
\hline $15-16$ & 1 & 5.6 & 8 & 66.7 & 9 & 30 \\
\hline $17-20$ & 3 & 16.8 & 3 & 25 & 6 & 19.9 \\
\hline Civil status & & & & & & \\
\hline Single & 17 & 94.4 & 10 & 83.3 & 27 & 90 \\
\hline Married & 1 & 5.6 & 2 & 16.7 & 3 & 10 \\
\hline & M & $\mathrm{SD}$ & M & SD & $t$ & $p$ \\
\hline Age & 26.22 & 5 & 28 & 4.285 & -1.04 & 0.38 \\
\hline
\end{tabular}


Table 1. (continued)

\begin{tabular}{|c|c|c|c|c|c|c|}
\hline \multicolumn{2}{|c|}{ Paranoid schizophrenia } & \multirow{2}{*}{$\frac{\text { Male }}{\%}$} & \multicolumn{2}{|c|}{ Female } & \multicolumn{2}{|c|}{ Total } \\
\hline$(n$ 31) & $n$ & & $n$ & $\%$ & $n$ & $\%$ \\
\hline Years of education & 13.11 & 2.987 & 16.08 & 1.564 & -3.553 & 0.001 \\
\hline \multicolumn{7}{|l|}{ Profession } \\
\hline Student & 10 & 55.6 & 1 & 8.3 & 11 & 36.7 \\
\hline Unemployed & 3 & 16.7 & 4 & 33.3 & 7 & 23.3 \\
\hline Retired & 0 & 0 & 0 & 0 & 0 & 0 \\
\hline \multicolumn{7}{|c|}{ Social economic class } \\
\hline Low class & 2 & 11.1 & 1 & 8.3 & 3 & 10 \\
\hline Medium class & 2 & 11.1 & 6 & 50 & 8 & 26.7 \\
\hline High class & 1 & 5.6 & 0 & 0 & 1 & 3.3 \\
\hline
\end{tabular}

$\mathrm{SD}=$ standard deviation.

Table 2. Means and SDs for both clinical groups

\begin{tabular}{|c|c|c|c|c|}
\hline & \multirow{2}{*}{$\frac{\text { Paranoid schizophrenia }}{\mathrm{M}}$} & \multicolumn{3}{|c|}{ Social anxiety } \\
\hline & & SD & M & $\mathrm{SD}$ \\
\hline BDI & 12.09 & 9.497 & 26.93 & 4.733 \\
\hline SBS & 32.09 & 4.337 & 14.30 & 2.890 \\
\hline OAS & 45.06 & 6.446 & 15.70 & 6.446 \\
\hline SCS_social acceptance & 25.67 & 14.204 & 34.50 & 12.093 \\
\hline SCS_rank & 26.83 & 19.433 & 36.66 & 12.688 \\
\hline FNE & 104.35 & 8.203 & 22.23 & 7.103 \\
\hline SIPAAS_anxiety/Distress & 113.35 & 8.722 & 22.36 & 5.756 \\
\hline SIPAAS_avoidance & 103.61 & 21.062 & 122.93 & 11.163 \\
\hline PC_total & 157.09 & 28.248 & 132.86 & 21.994 \\
\hline PC_frequency & 55.87 & 29.031 & 112.50 & 28.608 \\
\hline PC_conviction & 58.58 & 56.455 & 99.53 & 43.490 \\
\hline PC_distress & 42.64 & 20.703 & 33.96 & 13.956 \\
\hline BPRS_total & 80.74 & 29.524 & 56.53 & 16.761 \\
\hline BPRS_thought disturbance & 15.03 & 6.123 & 6.90 & 2.951 \\
\hline BPRS_affect & 12.87 & 5.116 & 15.40 & 4.709 \\
\hline BPRS_anergia/avolition & 18.25 & 8.869 & 9.96 & 4.460 \\
\hline BPRS_disorganization & 20.83 & 9.165 & 13.70 & 4.434 \\
\hline BPRS_hostility & 10.93 & 4.690 & 7.96 & 2.976 \\
\hline ELES_total & 52.61 & 14.936 & 39.73 & 9.839 \\
\hline ELES_threat & 22.06 & 7.243 & 14.33 & 5.850 \\
\hline ELES_submissiviness & 20.16 & 6.356 & 16.53 & 3.645 \\
\hline ELES_(un)valued & 10.38 & 4.216 & 8.86 & 2.270 \\
\hline AQ_total & 85.16 & 26.873 & 70.00 & 14.802 \\
\hline AQ_physical aggression & 21.70 & 9.070 & 16.63 & 7.863 \\
\hline AQ_verbal aggression & 14.45 & 5.926 & 12.06 & 3.503 \\
\hline AQ_anger & 20.41 & 8.077 & 17.06 & 5.205 \\
\hline AQ_hostility & 28.58 & 9.032 & 24.23 & 5.745 \\
\hline AAS__anxiety & 3.38 & 1.058 & 3.36 & 0.753 \\
\hline AAS_close & 2.58 & 0.854 & 2.44 & 0.674 \\
\hline AAS_depend & 2.77 & 0.673 & 2.72 & 0.524 \\
\hline CECA.Q antipathy (mother) & 22.54 & 10.075 & 20.66 & 8.339 \\
\hline CECA.Q neglect (mother) & 17.74 & 8.233 & 14.90 & 5.248 \\
\hline CECA.Q antipathy (father) & 27.82 & 8.268 & 21.60 & 5.899 \\
\hline
\end{tabular}


Table 2. (continued)

\begin{tabular}{|c|c|c|c|c|}
\hline & \multirow{2}{*}{$\frac{\text { Paranoid schizophrenia }}{\mathrm{M}}$} & \multicolumn{3}{|c|}{ Social anxiety } \\
\hline & & SD & $\mathrm{M}$ & SD \\
\hline CECA.Q neglect (father) & 21.51 & 7.119 & 20.26 & 6.389 \\
\hline CECA.Q physical abuse (mother) & 2.46 & 2.025 & 0.43 & 1.165 \\
\hline CECA.Q physical abuse (father) & 3.19 & 1.600 & 0.40 & 1.132 \\
\hline
\end{tabular}

$\overline{\mathrm{SD}}=$ standard deviation. BDI total = Beck's depression inventory: clinical depression. SBS total = Submissive Behaviour Scale: submissive behaviours. OAS total = Other as Shamer Scale: external shame. SCS = Social Comparison Scale (Allan \& Gilbert, 1995). FNE = Fear of Negative Evaluation: social anxiety. SIPAAS = Social Interaction Performance Anxiety Avoidance Scale: social anxiety-distress and avoidance of social situations. PC $=$ Paranoia Checklist: non-clinical paranoia. AAS = Adult Attachment Scale. ELES = Early Life Experiences Scale: recall of threatening family environments. CECA. $\mathrm{Q}=$ Child Experience of Care and Abuse Questionnaire. $\mathrm{AQ}=$ Aggression questionnaire: temperamental aggression. BPRS=Brief Psychiatric Rating Scale.

bullying since infancy to the present moment?' (note that experiences of bullying were clearly defined), we decided to perform planned contrasts using $t$-test independent samples to test for differences between the groups).

$T$-tests revealed statistically significant differences between the VB and the NVB.

As expected, the VB significantly report a higher 'frequency of paranoid thoughts' $(M=51.00, D P=20.6250)$ on the PC that range from interpersonal sensitivities and ideas of reference (such as other people are talking negatively behind my back) to conspiracy thoughts (being a victim of a conspiracy) allied to a higher 'conviction' $(\mathrm{M}=54.28, \mathrm{DP}=18.501)$ and 'distress' $(\mathrm{M}=41.61, \mathrm{DP}=$ 19.410) of those thoughts, than the NVB (frequency: $\mathrm{M}=32.05, \quad \mathrm{DP}=14.2262 ;$ conviction: $\mathrm{M}=36.42$, $\mathrm{DP}=$ 13.4796; distress: $\mathrm{M}=20.26$; $\mathrm{DP}=18.1959$ ). This difference between the VB and the NVB was statistically significant for the three dimensions of paranoid thoughts of the PC: frequency $t(59)=-4.154, p<0.001$; conviction $t(59)=-4.245$, $p<0.001$; distress $t(59)=-4.157, p<0.001$, respectively. Since the VB reported more paranoid beliefs than the NVB, we expected that the $\mathrm{VB}$ would show more symptoms of 'thought disturbance' in the BPRS, such as the presence of persecutory delusions than the NVB. Data showed that the VB displayed more symptoms of 'thought disorder' in the BPRS interview, such as delusions of persecutory content $(\mathrm{M}=12.35, \mathrm{DP}=6.8882)$, than the NVB $(\mathrm{M}=8.10, \mathrm{DP}=$ 3.36476). This difference between the groups was statistically significant $t(59)=-3.237, p<0.005$. In terms of 'disorganization' in the BPRS (another type of psychotic positive symptom), the VB showed more statistically significant 'conceptual disorganization-BPRS' $(M=18.69$, $\mathrm{DP}=8.7526)$ than the NVB $(\mathrm{M}=14.31, \mathrm{DP}=5.14298)$ $[t(59)=-2.439, p<0.050]$. Thus, the data is consistent with the idea that individuals that showed persecutory ideation reported more experiences of bullying. Furthermore, there was also a tendency for the VB to show more 'hostility' (BPRS) $(\mathrm{M}=9.833, \mathrm{DP}=4.3379)$ and affect symptoms, such as anxiety, in the BPRS $(\mathrm{M}=14.21, \mathrm{DP}=5.2985)$ than the NVB $(\mathrm{M}=8.684, \mathrm{DP}=3.17263$ for 'hostility' BPRS and
$\mathrm{M}=13.89, \mathrm{DP}=4.5569$ for 'affect' $\mathrm{BPRS}$ ); however, those differences were not statistically significant.

In contrast, the VB seemed to show less social anxiety (SIPAAS/Anxiety) $(\mathrm{M}=120.19, \mathrm{DP}=26.408)$ and fear of negative evaluations $(\mathrm{FNE})(\mathrm{M}=110.40, \mathrm{DP}=19.690)$ than the NVB $(\mathrm{M}=129.05, \mathrm{DP}=28.0386$ for SIPAAS / Anxiety and $\mathrm{M}=120.31, \mathrm{DP}=16.6375$ for $\mathrm{FNE}$ ). The difference between the groups on social anxiety, i.e., is the fear of social situations, was not statistical significant, but they differed on the FNE $(t(59)=2.029, p<0.050)$. Also, there was a tendency for the VB to report less submissive behaviours (SBS) $(\mathrm{M}=31.35, \mathrm{DP}=13.578)$ than the NVB $(\mathrm{M}=37.52, \mathrm{DP}=11.369)$. The difference between the groups was not strong enough to reach statistical significance $(t(59)=1.844, p=0.072)$.

Moreover, the VB demonstrated more physically aggressive and verbally aggressive behaviours in the AQ $(\mathrm{M}=21.23, \mathrm{DP}=8.953$ for physically aggressive behaviours; $\mathrm{M}=14.02, \mathrm{DP}=4.826$ for verbally aggressive behaviours) than the NVB $(\mathrm{M}=14.73, \mathrm{DP}=6.7151$ for physically aggressive behaviours; $\mathrm{M}=11.63, \mathrm{DP}=5.0904$ for verbally aggressive behaviours). These differences between the groups were statistically significant $(t(59)=-3.141, p<0.005)$ for physically aggressive behaviours and an almost significant $(t(59)=-1.727 p=0.093)$ for verbally aggressive behaviours, respectively (AQ). Also, the VB showed more anger in the AQ $(M=19.95, \mathrm{DP}=7.098)$ than the NVB $(\mathrm{M}=16.15, \mathrm{DP}=6.0557)$, and this difference between the groups was statistically significant $(t(59)=-2.114, p<0.050)$.

Since there is a well-established relationship in the literature between victimization at home (e.g., physical abuse by parents) and victimization at school (Baldry, 2003), we hypothesized that the VB group would show more experiences of abuse, antipathy/hostility and neglect by parents (CECA.Q), and memories of 'submissiviness' (ELES) than the NVB. Indeed, as expected, the VB recalled more childhood experiences of a threatening family environment 'ELES-Threat' $(M=20.42, \mathrm{DP}=7.2688)$, recalled more submissive behaviours towards family members 'ELES-Submissiviness' $\quad(\mathrm{M}=19.42, \quad \mathrm{DP}=5.513)$ 
and feeling more unvalued by these family members 'ELES(Un)valued' $(\mathrm{M}=10.21, \mathrm{DP}=3.4182)$ than the NVB $(\mathrm{M}=13.47$, $\mathrm{DP}=6.1405$ for 'ELES-Threat'; $\mathrm{M}=16.05$, $\mathrm{DP}=$ 4.7313 for 'ELES Submissiveness' and $\mathrm{M}=8.36, \mathrm{DP}=3.2865$ for 'ELES-(Un)valued'). Those differences between the two groups were statistically significant $(t(59)=-3.862$, $p<0.001)$ for 'ELES-Threat', $(t(59)=-2.448, p<0.030)$ for 'ELES Submissiveness' towards family members and almost statistical significant for 'ELES (Un)valued' $(t(59)=-2.006, p=0.0 .52)$.

Also, as expected, the VB reported more experiences of 'antipathy/hostility/rejection' (CECA.Q) ( $\mathrm{M}=23.45$, $\mathrm{DP}=9.295)$ and 'neglect' (CECA.Q) $(\mathrm{M}=17.54, \mathrm{DP}=7.188)$ by their mothers, and of antipathy/hostility/rejection (CECA.Q) $(\mathrm{M}=27.32, \mathrm{DP}=7.1412)$ and 'physical abuse' (CECA.Q) $(\mathrm{M}=2.083, \mathrm{DP}=1.9621)$ by their fathers than the NVB ('antipathy by mother' CECA.Q: $M=17.57$, $\mathrm{DP}=7.897$; 'neglect by mother' CECA.Q: $\mathrm{M}=13.68$, $\mathrm{DP}=$ 5.972; 'antipathy by father' CECA.Q: $M=19.05$, $\mathrm{DP}=5.892$ and 'physical abuse by father' CECA.Q: $\mathrm{M}=0.2667, \mathrm{DP}=1.0328$ ). All of these differences between the groups were statistically significant: 'antipathy by mother' (CECA.Q) $t(59)=-2.542, p<0.020$; 'neglect by mother' (CECA.Q) $t(59)=-2.192, p<0.035$; 'antipathy by father' (CECA.Q) $t(57)=-4.697, p<0.001$; and 'physical abuse by father' (CECA.Q) $t(49)=-4.305, p<0.001$. There were also tendencies for the VB to show more neglect by their fathers and physical abuse by their mothers (CECA. Q) than the NVB; however, those differences were not strong enough to reach statistical significance.

Finally, sexual abuse is a theme difficult to tackle due to social stigma; as expected, participants did not report many experiences of sexual abuse both on the BVQ in the case of sexual harassment by school colleagues and on the CECA.Q concerning abuse by family members and/or family friends. Also, although there was a tendency for the VB to show more external shame (OAS) than the NVB, this difference was not statistically significant (Table 3).

\section{DISCUSSION}

The aim of the study was to explore the differences between bully victims and non-victims in a sample of mentally ill patients. Our study set out to explore the impact of being a victim of bullying during childhood had in several psychological aspects of mentally ill individuals. Drawing from social mentality theory (Gilbert, 1989; Gilbert, 2001a, 2001b) and from research on bullying and paranoid ideation in a non-clinical population (Campbell \& Morrison, 2007), we hypothesized that bullying, as it dwells on traumatic experiences of being subjected to harm and being thwarted by others, should be reported both by individuals that suffer from social phobia and paranoid schizophrenia. Also, paranoid schizophrenics should significantly recall more experiences of being bullied. Our data, indeed, supported this hypothesis. Similar to findings of Campbell and Morrison's (2007) and Scheier et al. (2009), bullying is related to the presence of a paranoid ideation in a clinical population. This can be explained by the fact that bullying is a traumatic experience that simply can lead to the development of psychotic symptomatology or by the potential confound of memory biases of people who suffer from persecutory delusions. As they show ideas about others being potentially threatening and intending to harm them, they could therefore construct a biography on the basis of such experiences of defective behaviour, psychological and physical harm, thwarting and intention to put down and criticize, i.e., different bullying behaviours that would support and maintain their persecutory ideas.

However, results further suggested that bullying, contrary to the current DSM-IV (American Psychiatric Association, 1994) criteria for traumatic events, could constitute a traumatic event. It is related to psychosis in accordance to results from studies in non-clinical populations (Campbell \& Morrison, 2007; Gracie et al., 2007). We observed that victims of bullying suffer from neglectful, hostile and physically abusive parents. They also recall being more submissive towards family members and feeling less valued by them. Victims of bullying present not only aggressive temperaments (such as feelings of anger) but also, more frequently, non-psychotic paranoid ideation and positive psychotic symptoms such as thought disturbance (delusions). Data suggesting that individuals suffering from psychosis significantly showed more bullying experiences and aggressive temperaments fit rather well with the idea of two types of paranoia, the bad me versus the poor me (Bentall et al., 2001, Chadwick \& Trower, 1997). Our sample seemed to present the 'poor me' paranoia, i.e., they do not show signs of depression and seem to believe that the malevolence of others was underserved, hence, the underlying hostility and anger. This being the case, their attributional style for negative events, which is characterized by blaming other people (personalizing bias), may account for their apparent stable self-esteem, aggressive temperaments, and the absence of depressive symptomatology compared to individuals with social anxiety who seem to show more negative affect. Results also support the social mentality theory (Gilbert, Boxall, Cheung, \& Irons, 2005) and findings from studies such as Baldry's (2003), which showed that domestic violence is associated with being a victim of bullying. Read, Agar and Argyle, Aderhold's (2003) study showed a strong link between trauma and psychosis. Thus, a link may be present because children that are abused at home can be easy targets to school bullies. Furthermore, according to Gilbert et al. (2005) children that come from 
Table 3. Differences between victims of bullying versus non-victims of bullying

\begin{tabular}{|c|c|c|c|c|c|c|c|c|}
\hline \multirow[t]{2}{*}{ Victims of bullying group (VB) } & \multirow[b]{2}{*}{$\mathrm{M}$} & \multirow[b]{2}{*}{ SD } & \multirow[b]{2}{*}{$n^{\circ}$} & \multicolumn{5}{|c|}{ Non-victims of bullying group (NVB) } \\
\hline & & & & $\mathrm{M}$ & SD & $n^{\mathrm{o}}$ & $t$ & $p$ \\
\hline BDI total & 13.73 & 8.1332 & 42 & 14.15 & 6.585 & 19 & 0.214 & 0.832 \\
\hline SBS total & 31.35 & 13.578 & 42 & 37.52 & 11.364 & 19 & 1.844 & 0.072 \\
\hline OAS total & 42.35 & 17.496 & 42 & 37.78 & 15.364 & 19 & -1.029 & 0.310 \\
\hline SCS_social acceptance & 24.40 & 7.9512 & 42 & 23.05 & 7.627 & 19 & -0.633 & 0.531 \\
\hline SCS_social rank & 25.11 & 7.6356 & 42 & 23.57 & 7.911 & 19 & -0.712 & 0.482 \\
\hline FNE total & 110.40 & 19.690 & 42 & 120.31 & 16.674 & 19 & 2.029 & $0.049 * *$ \\
\hline SIPAAS_anxiety/distress & 120.19 & 26.408 & 42 & 129.05 & 28.039 & 19 & 1.164 & 0.253 \\
\hline SIPAAS_avoidance & 109.00 & 27.450 & 42 & 105.73 & 32.653 & 19 & -0.379 & 0.707 \\
\hline PC total & 146.90 & 54.710 & 42 & 88.73 & 43.462 & 19 & -4.452 & $0.000 *$ \\
\hline PC_frequency & 51.00 & 20.650 & 42 & 32.05 & 14.226 & 19 & -4.154 & $0.000 *$ \\
\hline PC_conviction & 54.28 & 18.501 & 42 & 36.42 & 13.480 & 19 & -4.245 & $0.000 *$ \\
\hline PC_distress & 41.61 & 19.410 & 42 & 20.26 & 18.196 & 19 & -4.157 & $0.000 *$ \\
\hline AAS_anxiety & 3.30 & 0.93311 & 42 & 3.50 & 0.877 & 19 & 0.805 & 0.426 \\
\hline AAS_close & 2.49 & 0.73574 & 42 & 2.56 & 0.854 & 19 & 0.289 & 0.775 \\
\hline AAS_depend & 2.73 & 0.571 & 42 & 2.79 & 0.673 & 19 & 0.383 & 0.704 \\
\hline ELES total & 50.07 & 13.906 & 42 & 37.89 & 10.959 & 19 & -3.684 & $0.001^{*}$ \\
\hline ELES_threat & 20.42 & 7.2688 & 42 & 13.47 & 6.141 & 19 & -3.862 & $0.000 *$ \\
\hline ELES_submissiviness & 19.42 & 5.5133 & 42 & 16.05 & 4.731 & 19 & -2.448 & $0.019^{* *}$ \\
\hline ELES_(un)valued & 10.21 & 3.4182 & 42 & 8.36 & 3.287 & 19 & -2.006 & 0.052 \\
\hline CECA.Q_antipathy(mother) & 23.45 & 9.2951 & 42 & 17.57 & 7.897 & 19 & -2.542 & $0.015^{* *}$ \\
\hline CECA.Q_antipathy(father) & 27.32 & 7.141 & 40 & 19.05 & 5.892 & 19 & -4.697 & $0.000 *$ \\
\hline CECA.Q_neglect (mother) & 17.54 & 7.188 & 42 & 13.68 & 5.973 & 19 & -2.192 & $0.034 * *$ \\
\hline CECA.Q_neglect (father) & 21.77 & 6.5378 & 40 & 19.00 & 6.912 & 19 & -1.466 & 0.152 \\
\hline CECA.Q_physical abuse (mother) & 1.22 & 1.8045 & 27 & 0.75 & 1.612 & 16 & -0.888 & 0.381 \\
\hline CECA.Q_physical abuse (father) & 2.083 & 1.9621 & 36 & 0.27 & 1.033 & 15 & -4.305 & $0.000 *$ \\
\hline CECA.Q_1st sexual experience & 0.62 & 1.6222 & 42 & 0.32 & 0.946 & 19 & -0.915 & 0.364 \\
\hline CECA.Q_sexual abuse & 0.17 & 1.0801 & 42 & 0.00 & 0.000 & 19 & -1.000 & 0.323 \\
\hline AQ total & 81.5 & 23.983 & 42 & 69.31 & 18.254 & 19 & -2.180 & $0.035^{* *}$ \\
\hline AQ _physical aggression & 21.23 & 8.957 & 42 & 14.73 & 6.715 & 19 & -3.141 & $0.003 *$ \\
\hline AQ_verbal aggression & 14.02 & 4.826 & 42 & 11.63 & 5.090 & 19 & -1.727 & 0.093 \\
\hline AQ_anger & 19.95 & 7.098 & 42 & 16.15 & 6.058 & 19 & -2.144 & $0.038^{* *}$ \\
\hline AQ_hostility & 26.28 & 8.486 & 42 & 26.78 & 6.399 & 19 & 0.256 & 0.799 \\
\hline BPRS_total & 73.23 & 29.056 & 42 & 59.10 & 18.266 & 19 & -2.303 & $0.025^{* *}$ \\
\hline BPRS_thought disorder & 12.35 & 6.889 & 42 & 8.10 & 3.365 & 19 & -3.237 & $0.002 *$ \\
\hline BPRS_disorganization & 18.69 & 8.753 & 42 & 14.31 & 5.143 & 19 & -2.439 & $0.018^{* *}$ \\
\hline BPRS_hostility & 9.83 & 4.378 & 42 & 8.684 & 3.713 & 19 & -1.057 & 0.297 \\
\hline BPRS_affect & 14.21 & 5.299 & 42 & 13.89 & 4.557 & 19 & -0.241 & 0.881 \\
\hline BPRS_anergia/avolition (negative symptoms) & 15.40 & 8.857 & 42 & 11.47 & 5.611 & 19 & -2.094 & $0.041^{* *}$ \\
\hline
\end{tabular}

$* p<0.005$

$* * p<0.050$

$\mathrm{SD}=$ standard deviation. BDI total = Beck's depression inventory: clinical depression. SBS total = Submissive Behaviour Scale: submissive behaviours. OAS total = Other as Shamer Scale: external shame. SCS = Social Comparison Scale. FNE = Fear of Negative Evaluation: social anxiety. SIPAAS = Social Interaction Performance Anxiety Avoidance Scale: social anxiety-distress and avoidance of social situations. PC = Paranoia Checklist: non-clinical paranoia. AAS = Adult Attachment Scale (Collins \& Read, 1990). ELES = Early Life Experiences Scale: recall of threatening family environments. CECA. $\mathrm{Q}=$ Child Experience of Care and Abuse Questionnaire. $\mathrm{AQ}=$ Aggression questionnaire: temperamental aggression. BPRS = Brief Psychiatric Rating Scale.

neglectful and threatening family environments learn to defend themselves either by fighting or fleeing. Thus, they will adopt certain behaviours and cognitions that will allow them to survive in the social world. Those behaviours are related to acting out and expressing anger to defend themselves. Cognitions are related to the being suspicious of others because they are potentially threatening (Gilbert et al., 2005; Ellett, Lopes \& Chadwick, 2003). Indeed, results supported the fact that victims of bullying, as adults, tend to be angry and express their anger physically. This may be a way to deal with negative and harmful experiences and defend their self-esteem, hence presenting an attributional style that blames others for negative and harmful experiences (personalizing bias) to maintain a positive self (Bentall, Kinderman, \& Kaney, 1994).

There are a few limitations of this study. First, it is a retrospective study, so we cannot explore whether individuals really suffered from traumatic experiences at school and at 
home. Instead, we rely on their memories which can easily be biassed. The case can be that what is reported is caused by being mentally ill, making it not a viable description of what really happened. Thus, we propose that to study clearly the impact of bullying in psychosis, researchers should use a longitudinal design instead of a cross-sectional design. The sample size was small, so we cannot infer that generally bullying is a frequent experience.

Nevertheless, the data is informative about the importance of childhood experiences at home and at school in the development of psychopathology and on the differences between social fears and paranoia. This is important since, lately in the literature, there is a tendency to associate social anxiety to paranoia in non-clinical populations (Freeman \& Garety, 2003; Freeman, 2007). This is based on the argument that neurosis and psychosis share psychological and symptomatological features, and both are influenced by the role of emotion such as anxiety and depression (e.g., affect is considered to be important in forming persecutory delusions (Freeman, 2007; Smit et al., 2006). Finally, in terms of clinical interventions, it is important to dwell on traumatic experiences and its associated affect, and to teach patients how to deal effectively with those memories to avoid anger and ruminations about paranoid ideas.

\section{REFERENCES}

Allan, S., \& Gilbert, P. (1995). A social comparison scale: Psychometric properties and relationship to psychopathology. Personality and Individual Differences, 19, 293-299.

Allan, S., \& Gilbert, P. (1997) Submissive behaviour and psychopathology. British Journal of Clinical Psychology, 36(4), 467-488.

Allan, S., Gilbert, P., \& Goss, K. (1994). An exploration of shame measures II: Psychopathology. Personality and Individual Differences, 17, 719-722.

American Psychiatric Association. (1994). The diagnostic criteria from $D S M-I V$. Washington, DC: American Psychiatric Association.

Baldry, A.C. (2003) Bullying in schools and exposure to domestic violence. Child Abuse \& Neglect, 27(7), 713-732.

Bebbington, P.E., Bhugra, D., Brugha, T., Singleton, N., Farrell, M., \& Jenkins, R. (2004). Psychosis, victimisation and childhood disadvantage. British Journal of Psychiatry, 185, 220-226.

Beck, A.T., Rush, A.J., Shaw, B.F., \& Emery, G. (1979). Cognitive therapy of depression. New York: Wiley.

Beck, A.T., Steer, R.A., \& Brown, G.K. (1996). Manual for the beck depression inventory-II. San Antonio, TX: Psychological Corporation.

Bentall, R.P. (1994). Cognitive biases and abnormal beliefs: Towards a model of persecutory delusions. In A.S. David, \& J. Cutting, (Eds.), The neuropsychology of schizophrenia. London: LEA, 337-360.

Bentall, R.P., \& Fernyhough, C. (2008). Social predictors of psychotic experiences: Specificity and psychological mechanisms. Environment and Schizophrenia, 34(6), 1012-1020.

Bentall, R.P., Corcoran, R., Howard, R., Blackwood, N., \& Kinderman, P. (2001). Persecutory delusions: A review and theoretical interpretation. Clinical Psychology Review, 21, 1143-1192.
Bentall, R. P., Kinderman, P., \& Kaney, S. (1994). The selfattributional processes and abnormal beliefs: Towards a model of persecutory delusions. Behaviour Research and Therapy, 32, 331-341.

Bifulco, A., Bernazzani, O., Moran, P.M., \& Jacobs, C. (2005). The Childhood Experience of Care and Abuse Questionnaire (CECA. Q): Validation in a community series. The British Journal of Clinical Psychology, 44, 563-581.

Buss, A.H., \& Perry, M. (1992). The Aggression Questionnaire. Journal of Personality and Social Psychology, 63(3), 452-459.

Campbell, M., \& Morrison, A.P. (2007). The relationship between bullying, psychotic-like experiences and appraisals in 14-16 year olds. Behaviour Research and Therapy, 45(7), 1579-1591.

Carvalho, S. (2006). Adaptacao da Child Experience and Abuse Questionnaire a uma amostra Portuguesa. Tese de Doutoramento: University of Oxford.

Chadwick, P.D.J., \& Birchwood, M.J. (1994). The omnipotence of voices: A cognitive approach to hallucinations. The British Journal of Psychiatry, 164, 190-201.

Chadwick, P.D.J., \& Trower, P. (1997). To defend or not to defend: A comparison of paranoia and depression. Journal of Cognitive Psychotherapy, 11, 63-71.

Clark, D.M. (2001). Social Attitudes Questionnaire, revised. Unpublished manuscript, University of Oxford.

D.M. Clark, \& A. Wells, (1995). A cognitive model of social phobia. In R.G. Heimberg, M. Liebowitz, D.A. Hope, \& Y Schneier (Eds.), Social phobia: Diagnosis, assessment and treatment. New York: Guilford.

Collins, N.L., \& Read, S.J. (1990). Adult attachment, working models and relationship quality in dating couples. Journal of Personality and Social Psychology, 58, 644-663.

Di'Nardo, P.A., \& Barlow, D.H. (1988). Anxiety disorders interview schedule-revised. New York: Graywind Publications.

Drury, V., Birchwood, M., Cochrane, R., \& MacMillan, F. (1996). Cognitive therapy and recovery from acute psychosis: A controlled trial. I. Impact on psychotic symptoms. The British Journal of Psychiatry 169, 593-601.

Ellett, L., Lopes, B., \& Chadwick, P. (2003). Paranoia in a nonclinical population of college students. The Journal of Nervous and Mental Disease, 191, 425-430.

Freeman, D. (2007). Suspicious minds: The psychology of persecutory delusions. Clinical Psychology Review, 27, 425-457.

Freeman, D., \& Garety, P.A. (2003). Connecting neurosis and psychosis: The direct influence of emotion on delusions and hallucinations. Behavior Research and Therapy, 41, 923-947.

Freeman, D., Garety, P.A., Bebbington, P.E., Smith, B., Rollinson, R., Fowler, D., Kuipers, E., Ray, K., \& Dunn, G. (2005a). Psychological investigation of the structure of paranoia in a non-clinical population. The British Journal of Psychiatry, 186, 427-435.

Freeman, D., Garety, P., Kuipers, E., Fowler, D., \& Bebbington, P.E. (2002). A cognitive model of persecutory delusions. The British Journal of Clinical Psychology, 41, 331-347.

Frith, C.D. (1992). The cognitive neuropsychology of schizophrenia. Hove: Lawrence, Erlbaum.

Garety, P.A., \& Hemsley, D.R. (1994). Delusions: Investigations into the psychology of delusional reasoning. Oxford: Oxford University Press.

Garety, P.A., Kuipers, E., Fowler, D., Freeman, D., \& Bebbington, P.E. (2001). A cognitive model of positive symptoms of psychosis. Psychological Medicine, 31, 189-195.

Gilbert, P. (1989). Human nature and suffering. London: Erlbaum. 
Gilbert, P. (1998). The evolved basis and adaptive functions of cognitive distortions. The British Journal of Medical Psychology, 71, 447-463.

Gilbert, P. (2001a). Evolutionary approaches to psychopathology: The role of natural defences. The Australian and New Zealand Journal of Psychiatry, 35, 17-27.

Gilbert, P. (2001b). Evolution and social anxiety: The role of attraction, social competition and social hierarchies. In F.R. Schneier (Ed.), Social Anxiety Disorder: The Psychiatric Clinics of North America (Vol. 24, pp. 723-751).Philadelphia, PA: Saunders.

Gilbert, P., Boxall, M., Cheung, M., \& Irons, C. (2005). The relation of paranoid ideation and social anxiety in a mixed clinical population. Clinical Psychology and Psychotherapy, 12, 124-133.

Gilbert, P., Cheung, M., Grandfield, T., Campey, F., \& Irons, C. (2003). Recall of threat and submissiveness in childhood: Development of a new scale and its relationship with depression, social comparison and shame. Clinical Psychology E Psychotherapy, 10, 108-115.

Goss, K., Gilbert, P., \& Allan, S. (1994). An exploration of shame measures I: "The Other as Shamer Scale". Personality and Individual Differences, 17, 713-717.

Gracie, A., Freeman, D., Green, S.. Garety P.A., Kuipers, E., Hardy, A., Ray, K., Dunn, G., Bebbington, P., \& Fowler, D. (2007). The association between traumatic experience, paranoia and hallucinations: A test of the predictions of psychological models. Acta Psychiatrica Scandinavica, 116(4), 280-289.

Kilcommons, A.M., \& Morrison, A.P. (2005). Relationships between trauma and psychosis: An exploration of cognitive and dissociative factors. Acta Psychiatrica Scandinavica, 112, 351-359.

Kuipers, E., Fowler, D., Garety, P.A., Chisholm, D., Freeman, D., Dunn, G., Bebbington, P.E., \& Hadley, C. (1998). The LondonEast Anglia randomised controlled trial of cognitive behaviour therapy for psychosis III: Follow-up and economic evaluation at 18 months. The British Journal of Psychiatry 173, 61-68.

Lopes, B., \& Pinto-Gouveia, J. (2010). A relação da paranóia com o afecto negativo em duas amostras não-clínicas da amostra Portuguesa. Psychologica, 52, 20-42.

Lopes, B., Pinto-Gouveia, J., \& Castilho, P. (2009). Estudo da vergonha. Cited in Lopes B. \& Pinto-Gouveia (2010) A relacao entre da paranoia com o afecto negativo em duas amostras nao-clinicas da amostra Portuguesa. Psychologica, vol. 52, 20-42 in press.

Lukoff, D., Nuechterlein, K.H., \& Ventura, J. (1986). Manual for the expanded Brief Psychiatric Rating Scale. Schizophrenia Bulletin, 12, 594-602.

Marks, I.M. (1987). Fears, phobias, and rituals: Panic, anxiety and their disorders. Oxford: Oxford University Press.

Marks, I.M., \& Nesse, R. (1994). Fear and fitness: An evolutionary analysis of anxiety disorders. Ethology and Sociobiology, 15, 247-261.

Matos, M., Lima, L., \& Carvalhosa, S. (2001). Bullying-a provocação e vitimação entre pares no contexto escolar Português. Análise Psicológica, 4(XIX), 523-537

Olweus, D. (1993). Bullying at school. Oxford: UK Blackwell Publishers.

Pinto-Gouveia, J., Cunha, M., \& Salvador, M.C. (2003). Assessment of social phobia by self-report questionnaires: The Social
Interaction and Performance Anxiety and Avoidance Scale and the Social Phobia Safety Behaviours Scale. Behavioural and Cognitive Psychotherapy, 31,291-311.

Pinto-Gouveia, J., Fonseca, L., Robalo, M., Allen, A., Matos, A., \& Gil, E. (1986). Ansiedade social: Utilização dos questionários de auto-resposta SAD, FNE, e SISST numa população portuguesa. Psiquiatria Clínica, 7, 43-48.

Read, J., Agar, K., Argyle, N., \& Aderhold, V. (2003). Sexual and physical abuse during childhood and adulthood as predictors of hallucinations, delusions and thought disorder. Psychological Psychotherapy, 76, 1-22.

Read, J., Van Os, J., Morrison, A.P., \& Ross, C.A. (2005). Childhood trauma, psychosis and schizophrenia: A literature review with theoretical and clinical implications. Acta Psychiatrica Scandinavica, 112, 330-350.

Ross, C.A., Anderson, G., Clark, P. (1994). Childhood abuse and the positive symptoms of schizophrenia. Hospital and Community Psychiatry 45, 489-491.

Scheier, A., Wolke, D., Thomas, D., Horwood, J., Hollis, C., Gunnel, D., Lewis, G., Thompson, A., Zamiit, S., Duffy, L., Salvi, G., \& Harrison, G. (2009). Prospective study of peer victimization in childhood and psychotic symptoms in a nonclinical population at age 12 years. Archives of General Psychiatry, 66(5), 527-536.

Shevlin, M., Dorahy, M., \& Adamson, G. (2007). Childhood traumas and hallucinations $>$ an analysis of the National Comorbidity Survey. Journal of Psychiatric Research, 41(3), 222-228.

Smith, B., Fowler, D.G., Freeman, D., Bebbington, P., Bashforth, H., Garety, P.A., Dunn, G., \& Kuipers, E. (2006). Emotion and psychosis: Links between depression, self-esteem, negative schematic beliefs and delusions and hallucinations, Schizophrenia Research 86, 181-188.

Smorty, A., Del Buffa, O., Maggino, F., \& Bacchereti, A. (2005). Parental monitoring and risk indicators in adolescence. Eta Evolutiva, 82, 82-88.

Solberg, M., Olweus, D. (2003). Prevalence estimation of school bullying with the Olweus Bully/Victim Questionnaire. Aggressive Behaviour, 29, 239-268.

Spencer, S.H., Donovan, C., Brechman-Toussaint, M. (1999). Social skills, social outcomes, and cognitive features of childhood social phobia. Journal of Abnormal Psychology, 21, 211-222.

Tariot P.N., Podgorski C.A., Blazina L., \& Leibivici A. (1993). Mental disorders in a nursing home: Another perspective. The American Journal of Psychiatry, 150(7), 1063-1069.

Tarrier, N., Yusupoff, L., Kinney, C., McCarthy, E., Gledhill, A., Haddock, G., \& Morris, J. (1998). Randomised controlled trial of intensive cognitive behavioural therapy for patients with chronic schizophrenia. British Medical Journal 317, 303-307.

Ventura, J., Green, M.F., Shaner, A., \& Liberman, R.P. (1993). Training and quality assurance with the brief psychiatric rating scale: 'The drift busters'. International Journal of Methods in Psychiatric Research, 3, 221-244.

Watson, D., \& Friend, R. (1969). Measurement of socialevaluative anxiety. Journal of Consulting and Clinical Psychology, $33,448-457$. 